AIAA-2005-1889

\title{
In-Vacuum Photogrammetry of a 10-Meter Solar Sail
}

\author{
Chris G. Meyer ${ }^{*}$ \\ Swales Aerospace, Hampton, Virginia \\ and \\ Thomas W. Jones ${ }^{\dagger}$, Charles B. Lunsford ${ }^{\ddagger}$, and Richard S. Pappa ${ }^{\S}$ \\ NASA Langley Research Center, Hampton, Virginia
}

\begin{abstract}
$\underline{\text { Abstract }}$
In July 2004, a 10-meter solar sail structure developed by L'Garde, Inc. was tested in vacuum at the NASA Glenn 30-meter Plum Brook Space Power Facility in Sandusky, Ohio. The three main objections of the test were to demonstrate unattended deployment from a stowed configuration, to measure the deployed shape of the sail at both ambient and cryogenic boom temperatures, and to measure the deployed structural dynamic characteristics (vibration modes). This paper summarizes the work conducted to fulfill the second test objective. The deployed shape was measured photogrammetrically in vacuum conditions with four 2-megapixel digital video cameras contained in custommade pressurized canisters. The canisters included high-intensity LED ring lights to illuminate a grid of retroreflective targets distributed on the solar sail. The test results closely matched pre-test photogrammetry numerical simulations and compare well with ABAQUS finite-element model predictions.
\end{abstract}

\section{$\underline{\text { Introduction }}$}

NASA's In-Space Propulsion (ISP) Program, managed by the Marshall Space Flight Center, has funded development for the past three years of two competing concepts for solar sail spacecraft. Solar sailing is a promising, future propulsion method that uses the small force of reflecting sunlight to accelerate the sail system in space without expendable propellants. The ISP program objective is to advance solar sail technology to a Technology Readiness Level of 6, and includes the manufacture and in-vacuum deployment of both 10-meter (in 2004) and 20-meter (in 2005) ground system demonstrators. One of two solar sail configurations under development is a "striped net" approach by L'Garde, Inc. This design uses four inflatably deployed, lightweight booms supporting a network of thin strings onto which four quadrants of ultra-thin aluminized membranes are attached. The NASA Langley Research Center (LaRC) is a member of the L'Garde solar sail team and is providing both experimental and analytical support for

\footnotetext{
* Mechanical Engineer, Member AIAA, now at PEBCO, Paducah, Kentucky

${ }^{\dagger}$ Research Engineer, Advanced Sensing and Optical Measurements Branch, Member AIAA

* Electrical Engineer, Advanced Sensing and Optical Measurements Branch

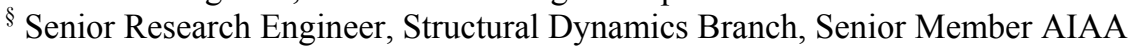


validating the structural characteristics of this unique, ultra-lightweight spacecraft concept [Refs. 1-2].

One of LaRC's responsibilities is to develop and apply photogrammetric methods to measure sail shape. The deployed shape provides important information for validating the accuracy of finite-element analytical modeling techniques. Photogrammetry is the science and art of calculating 3-D coordinates of individual targets or other distinguishing features on structures, with an acceptable degree of measurement precision. A minimum of two different camera views of each target is required for 3-D determination, but having four or more different camera views is preferable for improved reliability and accuracy. Using retroreflective circular targets typically provides the highest measurement accuracy and automation. This is the approach used to measure the L'Garde 10-m solar sail. References 3-4 provide details of photogrammetry technology, and Ref. 5 discusses previous experiences using photogrammetry to measure gossamer spacecraft structures such as solar sails.

The test discussed in this paper was conducted at the NASA-Glenn Space Power Facility (SPF) located at Plum Brook Station in Sandusky, Ohio [Ref. 6]. The SPF is the largest space environment simulation chamber in the world measuring 30 meters in diameter by 37 meters high. High vacuum levels $\left(10^{-6}\right.$ torr $)$ can be maintained inside the chamber, and cold environments $\left(-195{ }^{\circ} \mathrm{C}\right)$ are possible using variable-geometry cryogenic cold walls. The L'Garde solar sail test used a vacuum level of approximately 1 torr (sufficient for structural characterization) and instead of using the cryogenic cold walls, used local LN2 cold plates underneath each of the four cold-rigidizable solar sail booms instead.

This paper provides a brief summary of the photogrammetry aspects of the L'Garde 10-m solar sail test at Plum Brook. The following sections discuss the test configuration, the camera systems, pre-test photogrammetry simulations, test procedures, and test results.

\section{$\underline{\text { Test Configuration }}$}

Figure 1 shows the L'Garde 10-meter solar sail deployed inside the SPF vacuum chamber. (The dimension of 10 meters specifies the length along each side of the square sail.) The four aluminized, 2-micron-thick membrane quadrants are supported by a network of strings attached to four inflatable, thin-wall Kevlar booms that are rigidized in vacuum by cooling them to $-40{ }^{\circ} \mathrm{C}$ with $\mathrm{LN} 2$ cold plates. The booms are counterbalanced at 1-meter increments using pulleys and weights attached to stiff, overhead support trusses.

For the photogrammetry test, a total of $12430-\mathrm{mm}$ retroreflective circular targets were distributed on the sail in a uniform grid pattern. Additionally, eight $50-\mathrm{mm}$ retroreflective spherical targets were mounted on rigid poles screwed into threaded bushings in the floor along each side of the sail ( 2 per side). The photograph in Fig. 1 was taken with a handheld digital camera with the flash unit turned on. The flash brightly 
illuminates most of the photogrammetry targets on the nearest membrane quadrant and all of the unobscured spherical reference targets. Because retroreflective material does not illuminate at angles greater than $60^{\circ}$ off normal, most of the circular targets on the two membrane side quadrants and on the rear quadrant are not illuminated. The photogrammetry camera systems are located much higher in the chamber than this handheld camera, so that the majority of targets on the sail were well illuminated in all imagery used for photogrammetry.

Figures 2 and 3 show the photogrammetry camera locations in the test chamber. Each camera was installed in a pressurized canister mounted onto a pan-tilt unit that could be controlled from outside the chamber by an operator. The operator could also adjust the zoom lens, iris, and focus settings for each camera remotely from the control room of the facility. The camera support brackets were bolted to ledges located above each large chamber door and were about 16 meters above the sail. This camera geometry provided light-ray intersection angles of approximately $90^{\circ}$ in each direction, which is an optimal configuration for photogrammetry.

\section{Camera Systems}

To meet the need for full-field measurement of highly flexible, large gossamer structures such as solar sails, LaRC developed a multi-camera, high-resolution, digital imaging and recording system. The system records up to six synchronized, 2-megapixel digital video cameras (Dalsa 2M30) operating at frame rates up to $30 \mathrm{fps}$. Each camera has a motorized zoom lens with focal length settings of 16-160 mm. All imagery from the cameras is streamed in uncompressed digital form onto an array of high-speed disks. Various compression techniques (JPEG is typically used) can be applied when the images are recalled from the high-speed disk array and transferred to individual image files for analysis.

Figure 4 shows the internal components of each camera canister. The environmental constraints of working in vacuum presented the biggest challenge to the system design. The factors considered the most challenging were pressure and temperature, camera-to-computer communication, and lighting. The thermal sensitivity of the camera CCD from self-heating in this environment was a primary concern. To combat this effect the cameras were packaged in pressurized canisters with a regulated purge air supply to maintain stable temperatures and airflow. For data communications, the working distance from cameras to data acquisition computer exceeded the limit for copper wire. To support long distances, optical converters were added to the design to transfer all images digitally over fiber optic cables. Lighting requirements for target illumination were driven by the use of retroreflective measurement targets. Optimal photogrammetric centroiding accuracy with retroreflective targets requires concentric lighting at the camera. To satisfy this requirement and the effects of a vacuum environment, a custom high-intensity light emitting diode (LED) array was assembled for each camera package. This ring light was installed at the end of each canister, encircling the camera lens. The LED light intensity and all internal camera settings such as integration time could also be adjusted remotely from the control room of the facility. 


\section{Photogrammetry Simulations}

To verify that available camera locations would provide adequate coverage and measurement precision for the 10-meter sail, pre-test numerical simulations were performed using the Australis photogrammetry software [Ref. 7]. This work showed that it was possible to capture the entire sail in the frame of each camera and additionally provided estimates of measurement precision to be expected in the project. The predicted RMS measurement precision of approximately $0.5 \mathrm{~mm}$ was considered sufficient for this application. The array of targets used in the simulation was similar to that used in the test but did not exactly match quantity, orientation, or pitch as this information was not available when the simulations were performed. Camera parameters such as pixel size and number of pixels on the CCD were obtained from manufacturer specifications, and camera coordinates were derived from facility drawings. This information provided the elements necessary for a photogrammetric network simulation in Australis.

Figure 5 shows the pre-test simulated images for each of the four camera positions, and Fig. 6 shows corresponding camera images obtained in the photogrammetry test. During the test, the chamber lights were turned off and the canister LED ring lights were activated to illuminate the grid of measurement targets. Nearly all of the targets on the sail were well illuminated from each camera position, and there were only a few "hot spots" in the images caused by undesirable specular reflections from the aluminized membrane (such as near the upper-left corner in the Camera 1 image). Comparison of Figs. 5 and 6 shows excellent correlation of pre-test simulated images with those recorded in the test.

\section{$\underline{\text { Test Procedures }}$}

Prior to making shape measurements, the four digital-video camera systems were also used to record solar sail deployment. During sail deployment the chamber lights were turned on and the LED ring lights on the camera canisters were turned off. Figure 7 shows images of the deployed sail under these lighting conditions. Although these images cannot be used for photogrammetry, they do illustrate the multiple-purpose functionality of the custom-made camera systems developed for this project. Comparing Fig. 7 with Fig. 6, it is clear that the same equipment can be used to acquire significantly different types of information.

Images for photogrammetry (Fig. 6) are purposely underexposed to simplify locating and centroiding the illuminated measurement targets. However, the lack of most background information in the images can make it difficult to identify specific targets during data analysis. Therefore, during test set up several additional retroreflective targets were placed around the perimeter of the sail for visual reference and scaling purposes. These additional targets are also useful during comparison of different data sets (for example, the datasets acquired with uncooled versus cooled sail booms) because they are stationary points whereas the sail targets can change their 3-D locations somewhat with test condition. One stationary $30-\mathrm{mm}$ target was attached to the floor between the center 
and end of each edge, and a group of $30-\mathrm{mm}$ targets indicating quadrant number was attached to the floor near the middle of each edge. Additionally, two $50-\mathrm{mm}$ retroreflective spheres on rigid poles were placed along each edge. These stationary spherical targets located above the floor were used for scaling and also provided threedimensionality, which improves photogrammetric data analysis accuracy.

Once these reference targets had been installed, their coordinates were measured with a high-precision industrial photogrammetry system, the V-STARS INCA 3 [Ref. 8]. The portable 8-megapixel INCA 3 camera used with the V-STARS software has a measurement accuracy of better than 1 part in 150,000 of object size, which is at least five to ten times higher than that obtainable with the four stationary, 2-megapixel photogrammetry cameras. Distances measured with V-STARS between adjacent spherical targets were used as scale distances in the test data analysis. All data collected in the photogrammetry tests with the four stationary digital-video cameras in canisters were processed using the PhotoModeler commercial photogrammetry software [Ref. 9]. Although the V-STARS software is much more automated than PhotoModeler, it could not be used to analyze the test data because it can only process images from the INCA 3 camera.

Photogrammetry data were acquired at three test conditions: ambient pressure (1 atmosphere), vacuum conditions ( 1 torr), and vacuum conditions ( 1 torr) with cryogenic cooling of the sail booms. Localized cooling using LN2 cold plates rigidized the inflatable sail booms at temperatures of approximately $-40{ }^{\circ} \mathrm{C}$. Full-field sail images were acquired at all three test conditions and were repeated at ambient pressure following repressurization for a consistency check. Additionally, single-quadrant images were obtained of quadrant 4 only at each test condition and also repeated in ambient for a consistency check. These single-quadrant measurements provided somewhat better measurement precision for quadrant 4 , but of course at the expense of measuring only one-fourth of the sail. A dynamic measurement was also made of quadrant 4 during the dynamic testing phase of the project while an electromagnetic shaker excited one of the booms vertically. However, in the data analysis it was found that the amplitude of motion, being in the 2-3 mm range, was insufficient to achieve good photogrammetric tracking of the sail motion. This paper presents results for only the full-field static shape measurements for the last two test conditions.

\section{$\underline{\text { Results }}$}

Figure 8 shows the photogrammetry results obtained in vacuum conditions prior to rigidizing the booms. Of the 124 targets on the sail, only 3 targets could not measured in this test because of insufficient contrast in the images at those locations. Note that this grid of points is a 3-dimensional object that can be reoriented interactively inside PhotoModeler. By viewing the data in Fig. 8 from several other directions, the photogrammetrically calculated points are clearly seen to have a scalloped shape just as the sail surface does, and the targets in all four quadrants display regular spacing and spatial consistency. In conjunction with calculated precision estimates (not shown), this result is judged to be an accurate measurement of the deployed sail shape. 
A similar set of measurements was made after the sail booms were rigidized by cryogenic cooling from underneath. Because the photogrammetry targets placed around the periphery of the sail remained stationary between tests, the two data sets (before and after boom rigidization) could be directly compared by aligning the stationary points. This comparison, shown in Fig. 9, clearly revealed that the boom cooling created a systematic change in sail shape. In this figure the dots indicate the sail shape before boom cooling and the attached vectors show the change in shape resulting from the boom cooling. These results show a consistent downward bending of the four sail booms of about $25 \mathrm{~mm}$ at the tips, implying nonuniform cooling through the thickness of the booms. These measurements provide important information for correlating with analytical thermal analyses and for adjusting the boom insulation design as necessary for proper performance in space.

All photogrammetry results computed with PhotoModeler can be exported for additional analysis with other programs. Figure 10 shows one use of this data export capability. The 3-D target coordinates shown in Fig. 8 for the test in vacuum with uncooled booms are plotted on the left side of Fig. 10 and compared with corresponding predictions made using the ABAQUS finite-element program plotted on the right side. Considerable useful information is provided by this type of full-field sail shape comparison for updating the ABAQUS structural analytical model as necessary to match the test results more closely.

\section{Conclusions}

Overall these photogrammetry tests were considered a great success. All of the cameras, canisters, and image recording hardware operated flawlessly and provided quality imagery for both the photogrammetry analyses and also for documenting sail deployment. By using a darkened test chamber and adjusting the variable-intensity LED ring lights on the camera canisters as needed, all photogrammetry images had high contrast between the bright measurement targets and the dark image background, which simplified data analysis. All images were processed with the PhotoModeler commercial software without undue difficulty, and providing 3-D experimental results useful for correlation with analytical models. It is unfortunate that the dynamic measurements were not successful because of inadequate excitation amplitudes. However, it is anticipated that these measurements will be attempted again in the 20-meter test in July 2005 using greater excitation amplitudes that should allow high-quality results to also be obtained for full-field characterization of solar sail system dynamics.

\section{Acknowledgments}

The authors acknowledge Mr. David Sleight of NASA LaRC for providing the ABAQUS analysis shown in Fig. 10, and Mr. Bill Goad (retired) of NASA LaRC for outstanding support during development of the digital video camera systems for this project. This work was sponsored in part by NASA's In-Space Propulsion program managed by the Marshall Space Flight Center. 


\section{$\underline{\text { References }}$}

1. Lichodziejewski, D., Derbes, B., Reinert, R., Belvin, W. K., Slade, K. N., and Mann, T. O., "Development and Ground Testing of a Compactly Stowed Scalable Inflatably Deployed Solar Sail," AIAA Paper 2004-1507, April 2004.

2. Sleight, D. W., Michii, Y., Lichodziejewski, D., Derbes, B., Mann, T.O., Slade, K. N., and Wang, J. T., "Finite Element Analysis and Test Correlation of a 10-Meter Inflation-Deployed Solar Sail,” AIAA Paper 2005-2121, April 2005.

3. Mikhail, E. M., Bethel, J. S., and McGlone, J. C., Introduction to Modern Photogrammetry, John Wiley and Sons, New York, 2001.

4. Atkinson, K. B. (editor), Close Range Photogrammetry and Machine Vision, Whittles Publishing Company, 2001.

5. Pappa, R. S., Jones, T. W., Black, J. T., Walford, A., Robson, S., and Shortis, M. R., "Photogrammetry Methodology for Gossamer Spacecraft Structures," Sound and Vibration, Vol. 36, No. 8, August 2002, pp. 12-21.

6. NASA Plum Brook Space Power Facility, Website: http://facilities.grc.nasa.gov/spf/.

7. Photometrix Ltd., Australis 6.0 User's Guide, 2004.

8. Geodetic Services V-STARS system, Website: http://www.geodetic.com/inca3/.

9. Eos Systems, Inc., PhotoModeler Pro 5.0 User's Guide, 2004. 


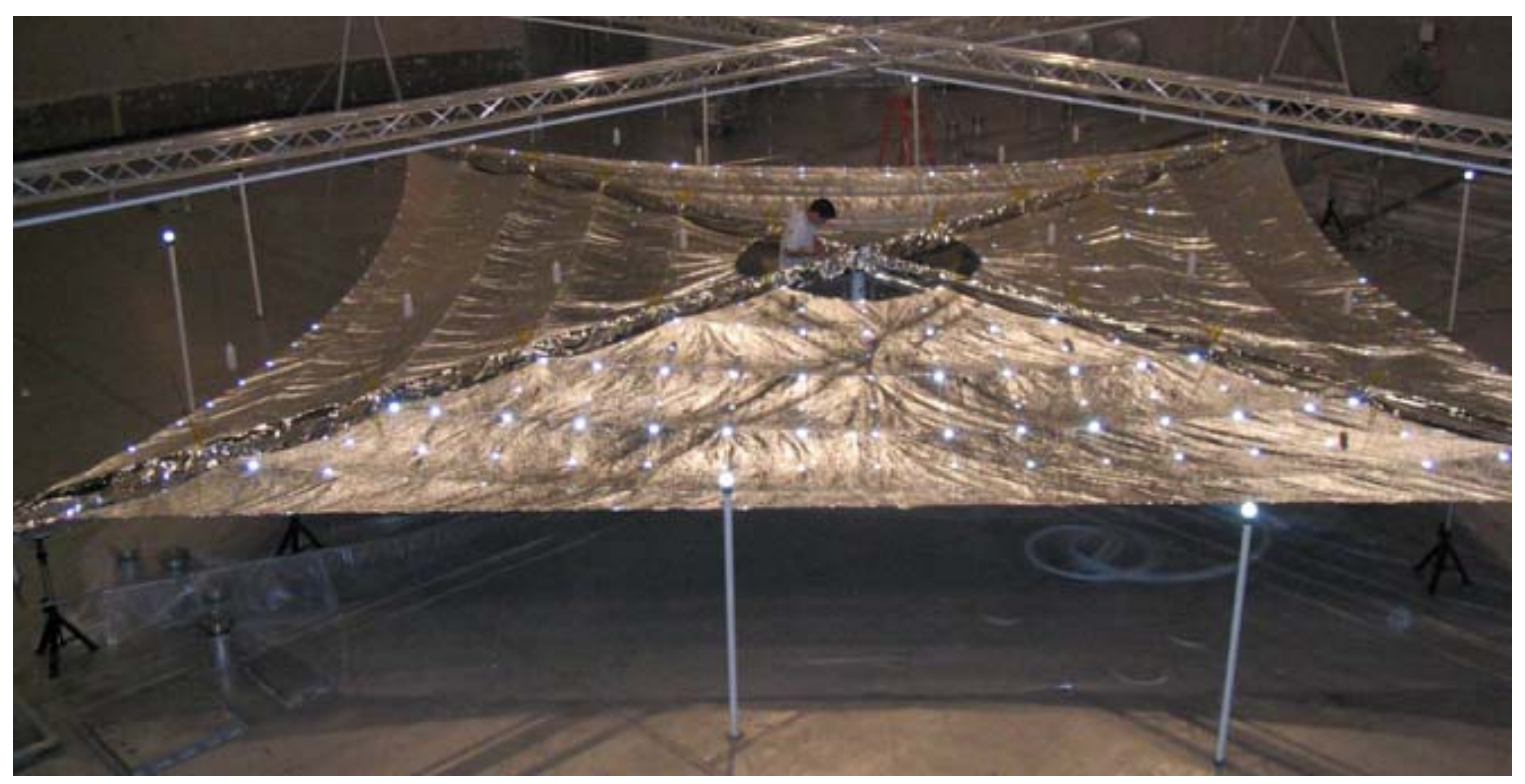

Figure 1. L'Garde 10-Meter Solar Sail in Plum Brook SPF Vacuum Chamber (Photogrammetry Targets on Front Quadrant are Illuminated by Camera Flash)

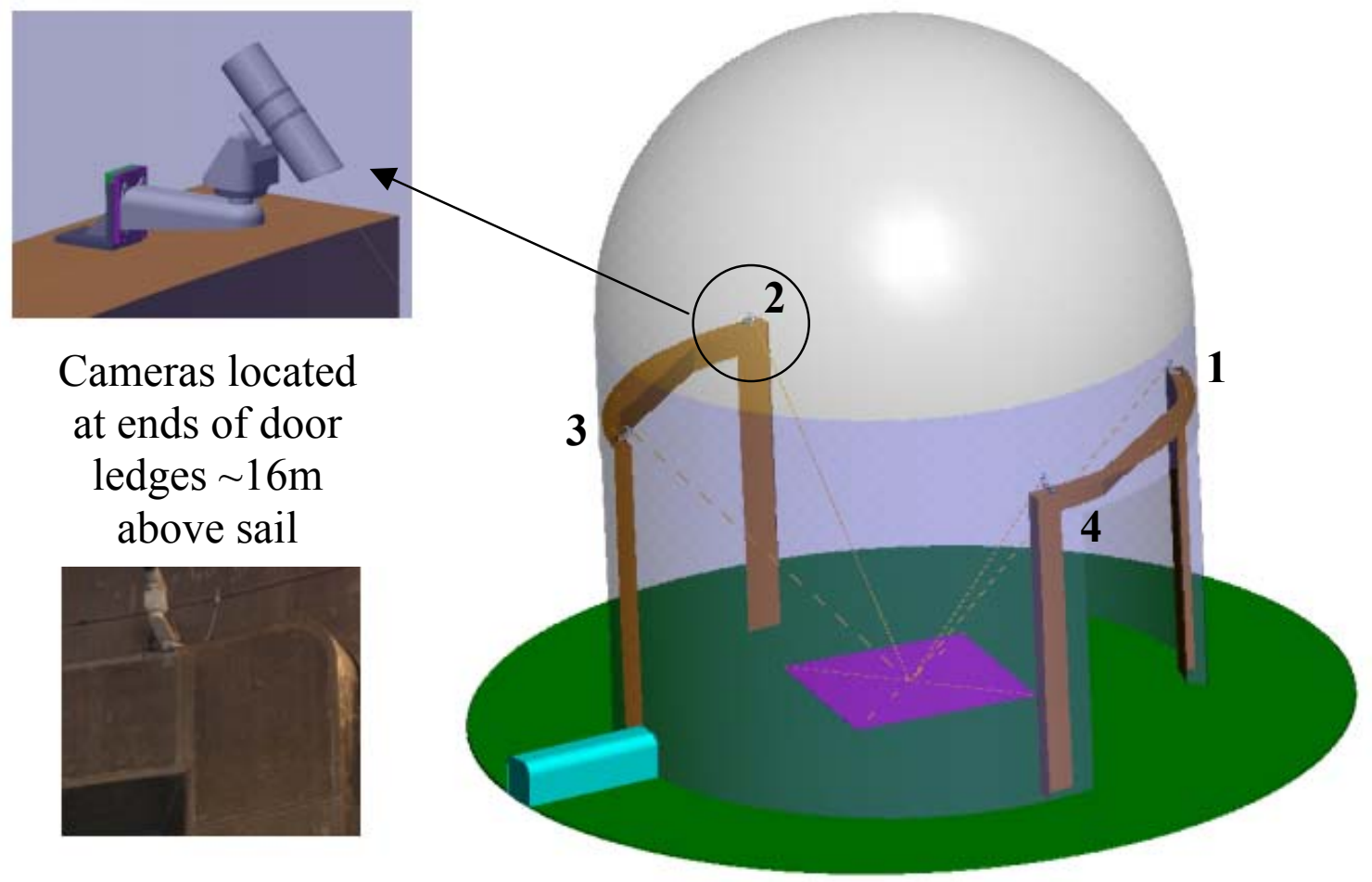

Figure 2. Photogrammetry Camera Locations 


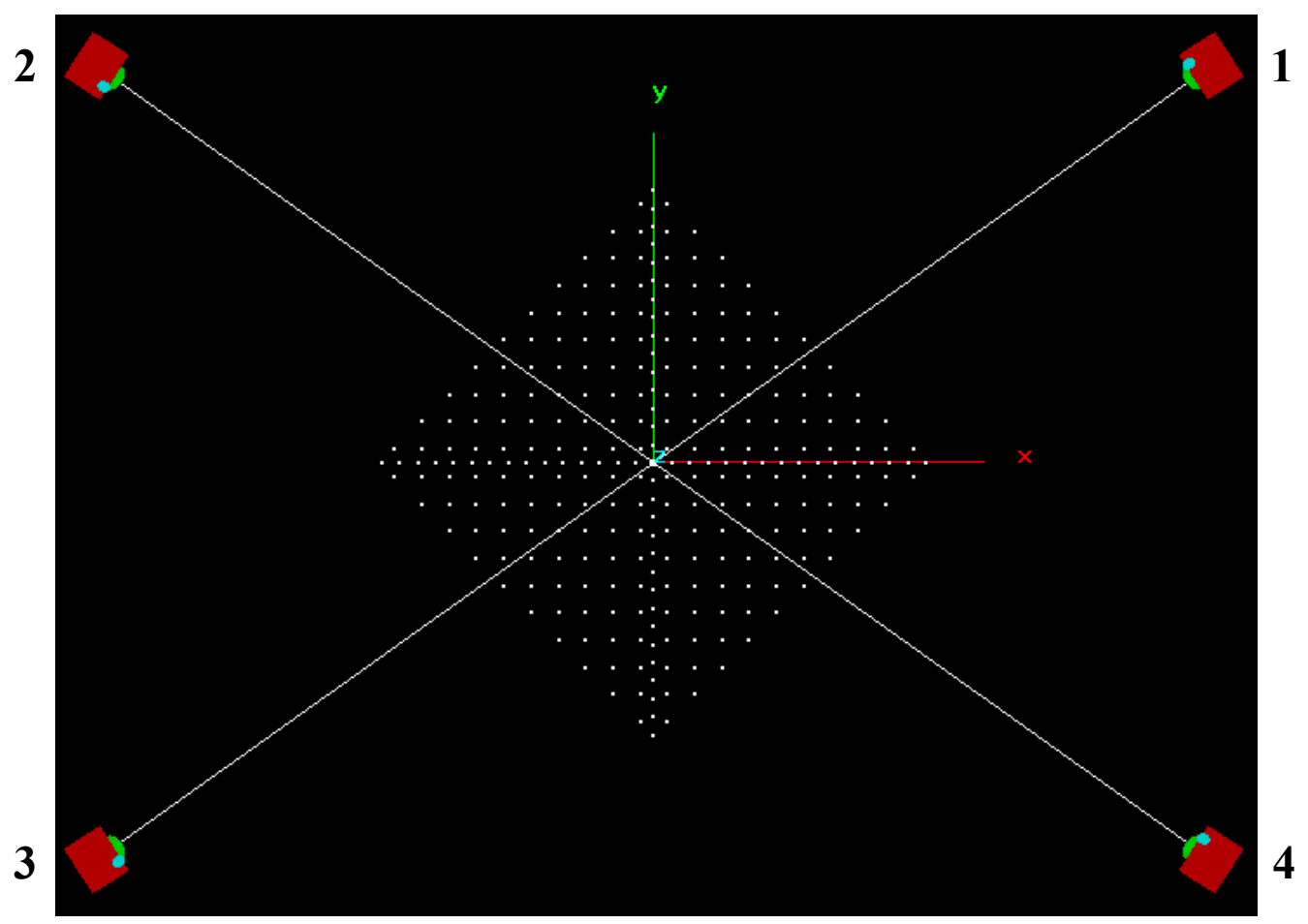

Figure. 3. Plan View of Camera Locations

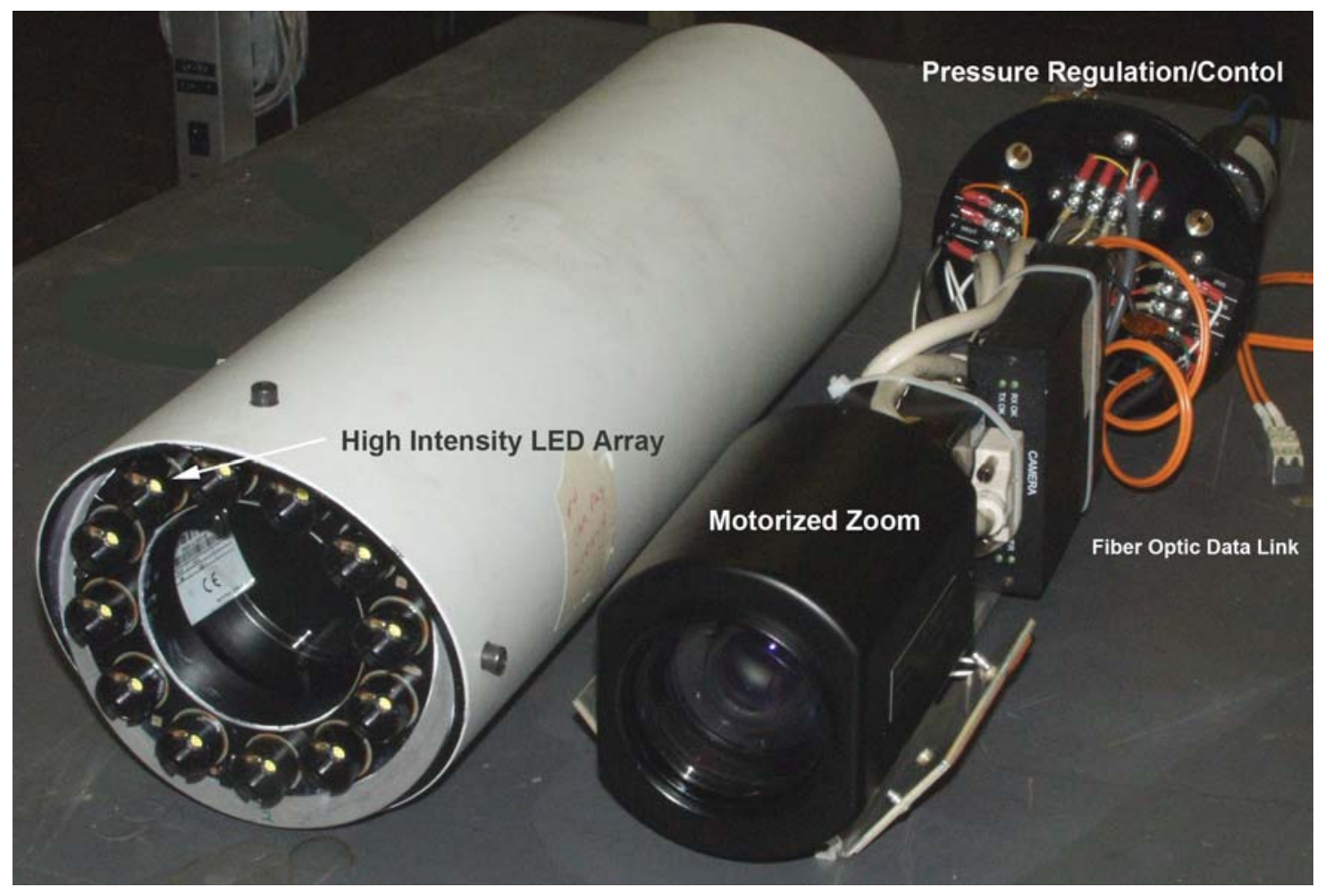

Figure 4. Camera Canister Components

American Institute of Aeronautics and Astronautics 


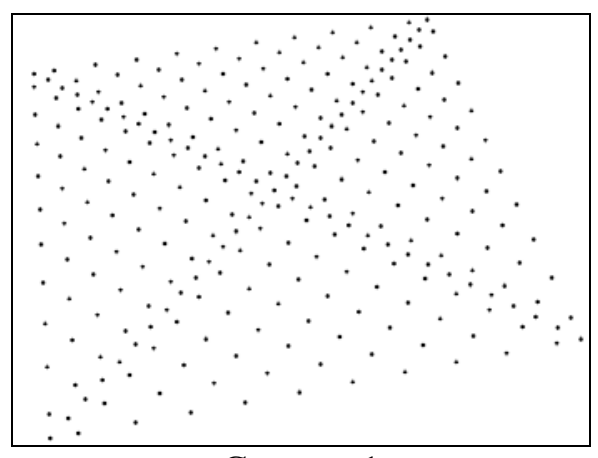

Camera 1

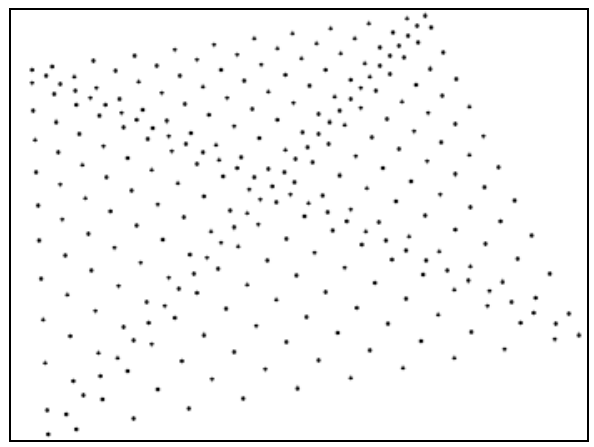

Camera 3

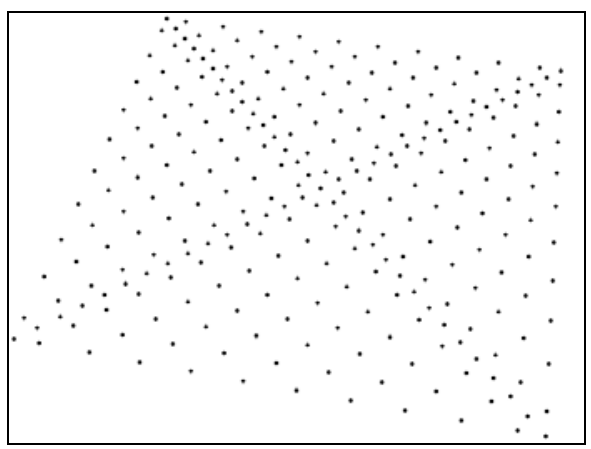

Camera 2

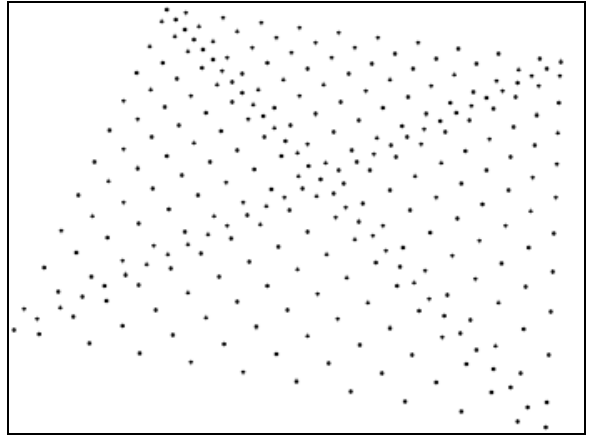

Camera 4

Figure 5. Pre-Test Simulated Images

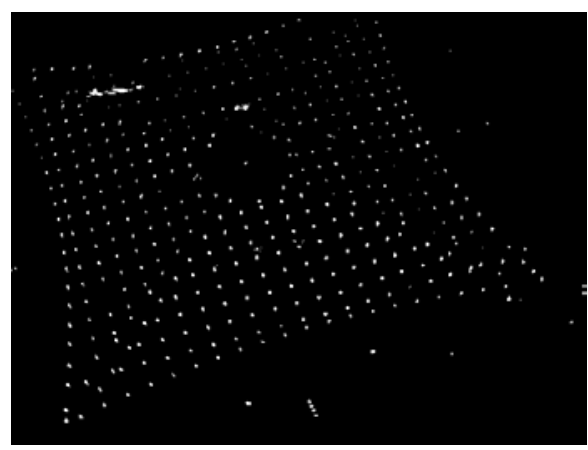

Camera 1

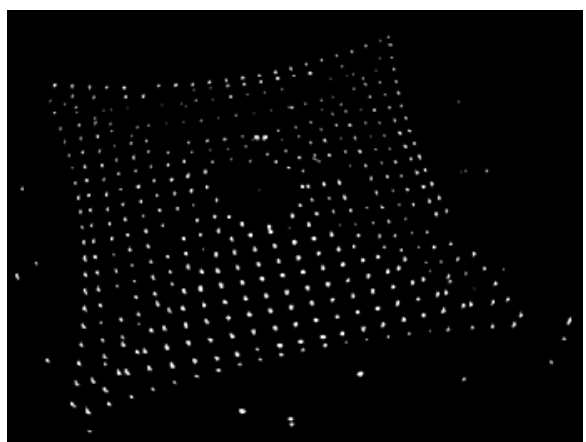

Camera 3

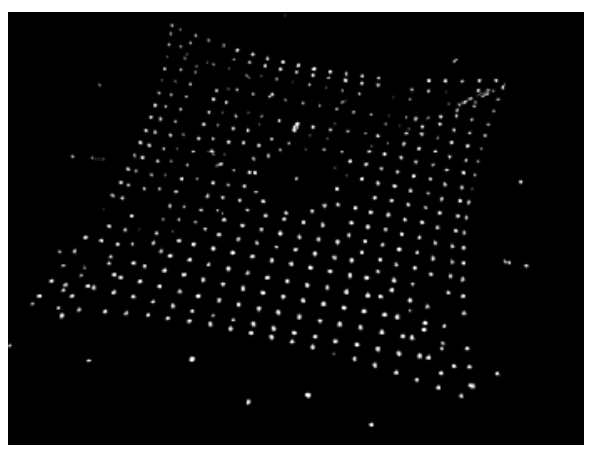

Camera 2

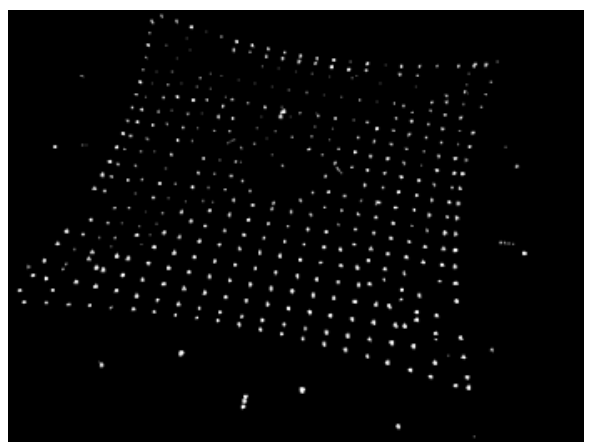

Camera 4

Figure 6. Camera Images in Darkened Chamber and LED Target Illuminators Turned On 


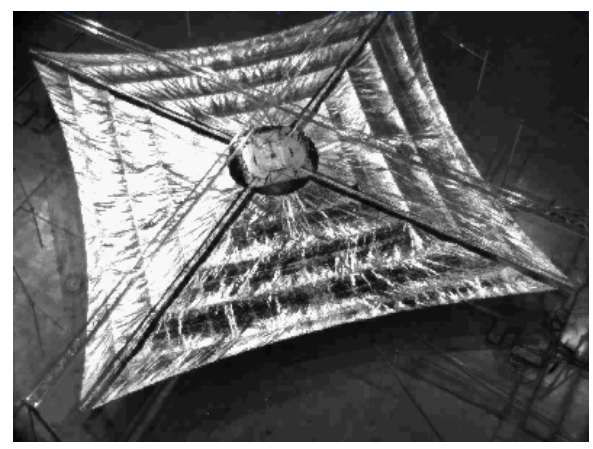

Camera 1

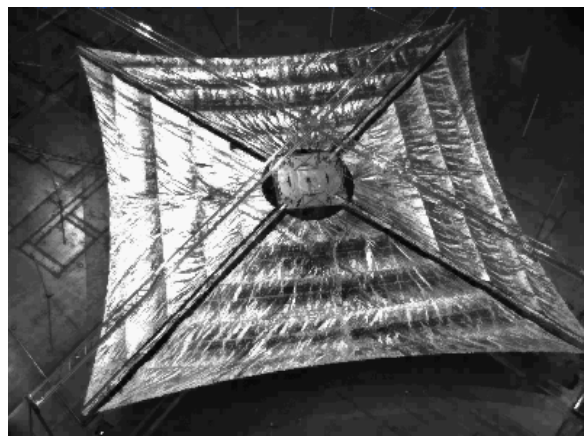

Camera 3

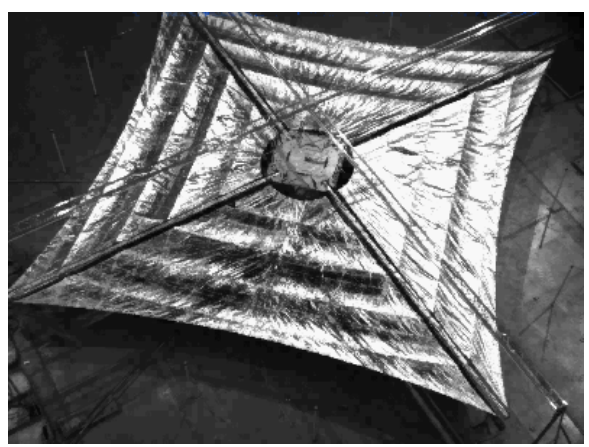

Camera 2

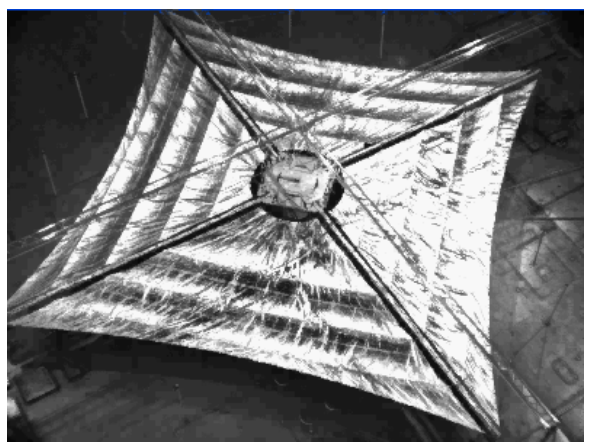

Camera 4

Figure 7. Camera Images in Ambient Lighting and LED Target Illuminators Turned Off

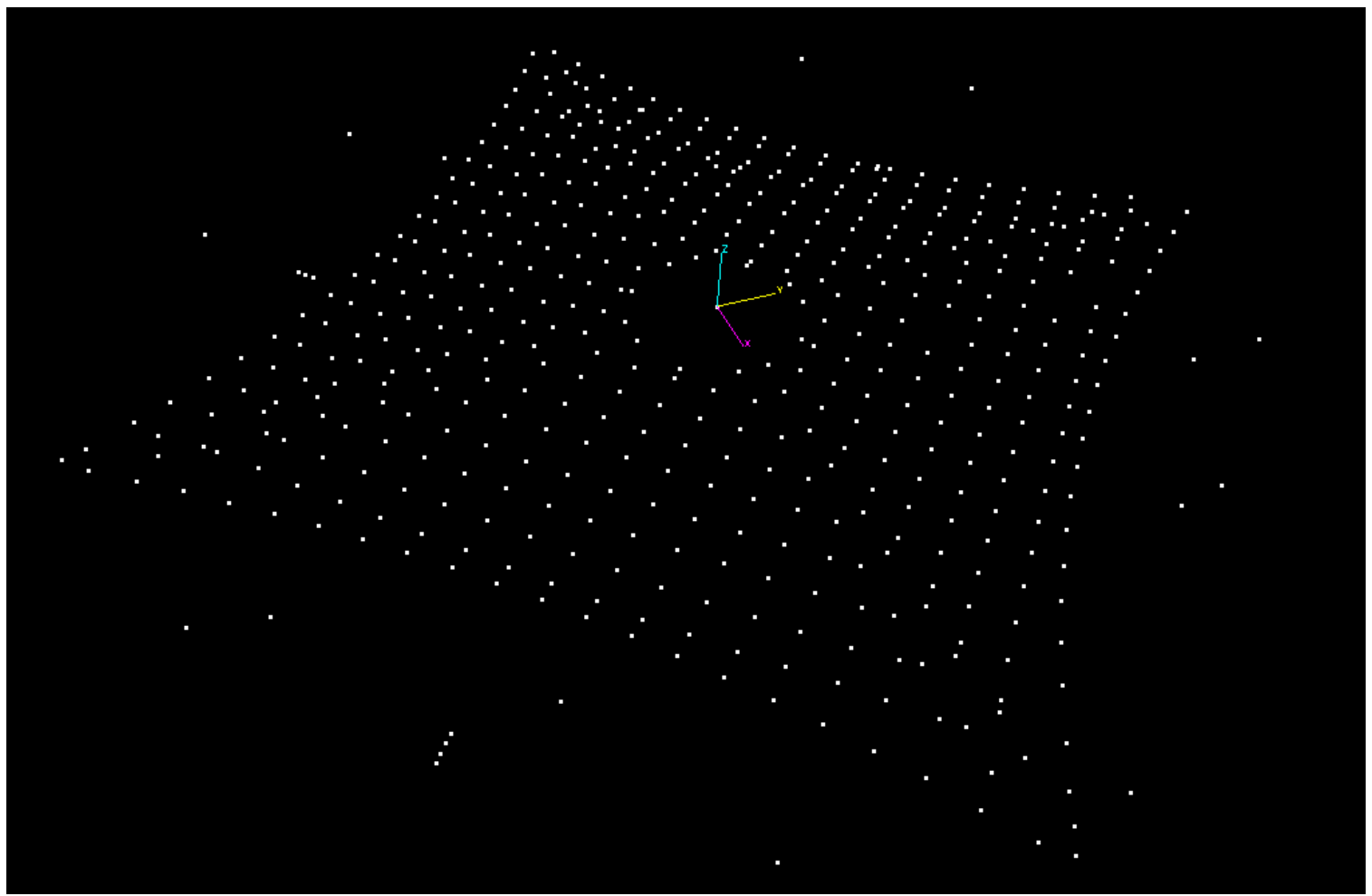

Figure 8. 3-D Photogrammetry Results in Vacuum with Unrigidized Booms 


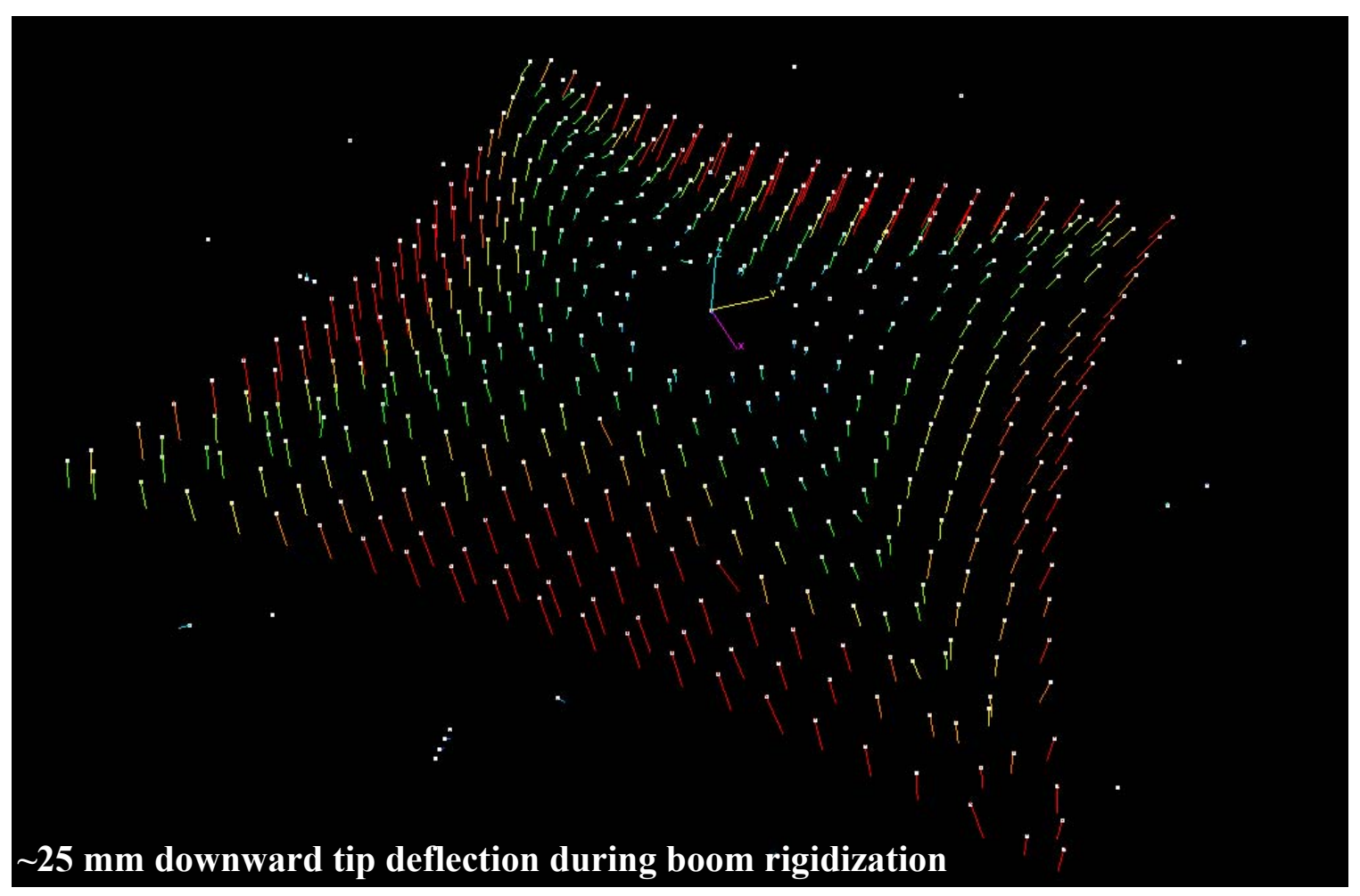

Figure 9. Shape Change During Boom Rigidization Measured Using Photogrammetry

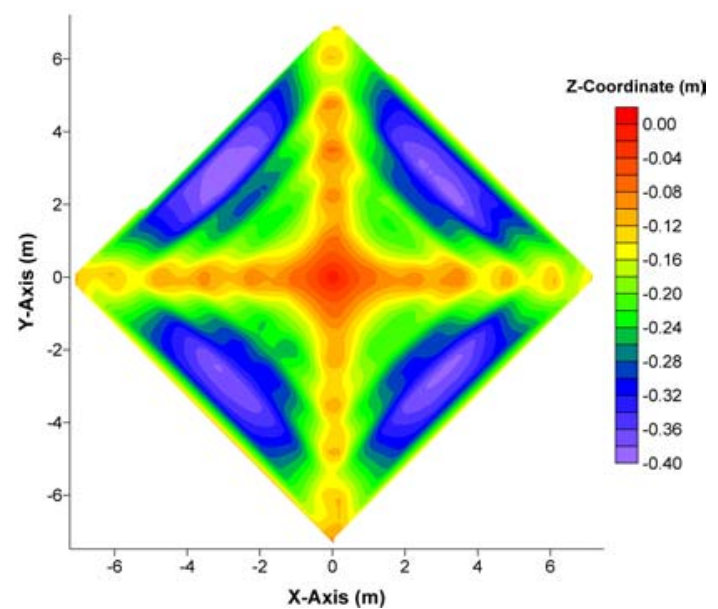

Photogrammetry Measurements

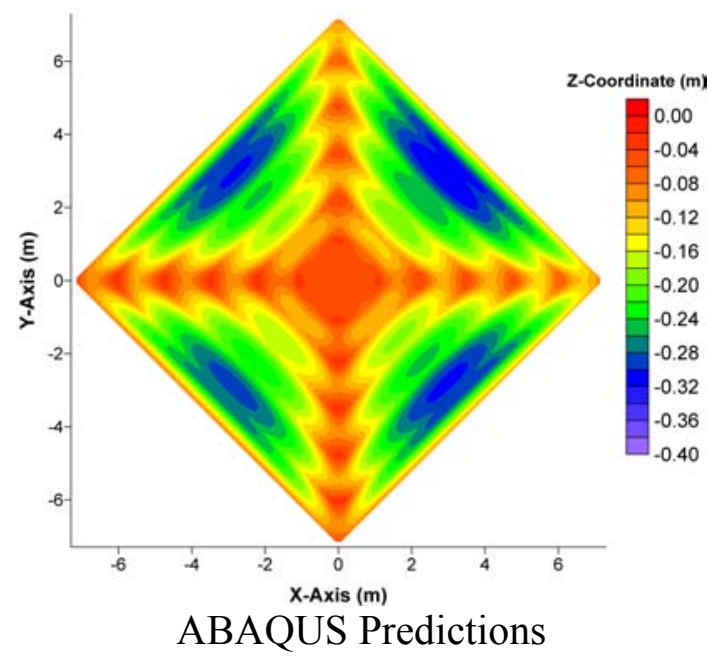

Figure 10. Comparison of Photogrammetry Results with Finite Element Predictions 